\title{
Raman spectroscopy of the laser irradiated titanium dioxide
}

\author{
${ }^{1}$ Strelchuk V.V., ${ }^{1}$ Budzulyak S.I., ${ }^{2}$ Budzulyak I.M., ${ }^{2}$ Ilnytsyy R.V., \\ ${ }^{2}$ Kotsyubynskyy V.O., ${ }^{2}$ Segin M.Ya., ${ }^{2}$ Yablon L.S. \\ ${ }^{I} V$. E. Lashkaryov Institute of Semiconductor Physics, NAS of Ukraine, \\ 41, pr. Nauky, 03028, Kyiv, Ukraine \\ ${ }^{2}$ Vasyl Stefanuk Precarpatian National University, \\ 57, Shevchenko str., 76025, Ivano-Frankivsk Ukraine
}

\begin{abstract}
Evolution of anatase phase for the $\mathrm{TiO}_{2}$ nanocrystals at their laser irradiation is researched by the method of combinational light dispersion. The observed changes of intensity, frequency and halfwidth of $\mathrm{TiO}_{2}$ phonon lines are interpreted taking into account the effects of nonstoichiometry, superficial strains and phonon confinement. The found out parameter changes in the low frequency $E_{g}$ mode show that laser irradiation results in substantial improvement of the structural ordering in the area of $\mathrm{TiO}_{6}$ octahedrons bonds.
\end{abstract}

Keywords: Titanium dioxide, Intercalation, Anatase, Raman spectroscopy.

Manuscript received 04.05.10; accepted for publication 08.07.10; published online 30.09.10.

\section{Introduction}

Nowadays titanium dioxide is used as electrode material for the lithium power sources [1-3]. The nanodispersed forms of $\mathrm{TiO}_{2}$ are very important, as they give possibilities to carry out lithium intercalation in the "host"-material more effectively. However, even in the case of nanodispersed $\mathrm{TiO}_{2}$ using the availability of their «guest» positions is supposed to be improved. Therefore, the various external influences are used for their activation, which allow to increase «guest» loading and, accordingly, to form the power sources with higher specific power characteristics.

\section{Experimental}

Laser radiation was used to activate "guest" positions in nanodispersed $\mathrm{TiO}_{2}$ of the firm «Aldrich» (average size of particles $<25 \mathrm{~nm}$, anatase phase); laser radiation was made in vacuum ( $\mathrm{P}=10^{-5}$ Torr) by using Nd:YAG-laser that operates in the mode of the modulated Q-factor (wavelength is $\lambda=1.06 \mu \mathrm{m}$, pulse duration is $\tau=10 \mathrm{~ns}$, frequency of these pulses is $\mathrm{f}=28 \mathrm{~Hz}$, energy in the pulse is $E=0.02-0.04 \mathrm{~J}$, duration of irradiation is $\mathrm{t}=4.5$ $5.5 \mathrm{~min})$.

Main structural transformations during laser radiation with nanodispersed titanium dioxide lie in a change of elementary cell parameters (Table 1) (experimental error $\pm 0.0001 \ldots 0.0005 \mathrm{E}$ ) and Frenkel defects formation. At the same time, existent point defects get sufficient energy for their migration inside the bulk. Laser radiation has the biggest influence on materials with availability of native point defects and considerable heterogeneities (including other phases, interfaces, etc). Co-ordination disturbance of titanium and oxygen atoms is probably related to the appearance of fields of thermoelastic strains in their surrounding as a result of laser beam thermal influence. Localization of thermal energy causes the change in lattice parameters, which at the same time influences on the sizes and charge state of energy favorable «guest» positions for the intercalated lithium ions. The average size of coherent-scattering regions for different modes of laser irradiation did not change for the methodic error.

$\mathrm{X}$-ray researches were realized using the diffractometer STOE STADI P with the linear positionsensible detector (PSD) accordingly to the scheme of the modified Gin'e geometry, in the Bregg-Brentano mode $\left(\mathrm{CuK} \alpha_{1}{ }^{-}\right.$radiation; $\lambda=1.54060 \mathrm{E}$; Iogann type Gebended monochromator [111]; scanning step is $0.015^{\circ} 2 \theta$, scanning time in the step is $400 \mathrm{~s}$ ).

Raman spectra of nanodispersed titanium dioxide researches were carried out using the triple spectrometer of T64000 Jobin-Yvon (1800/mm, settling ability $\approx 1 \mathrm{~cm}^{-1}$ ) in geometry of reverse dispersion, using the line $488 \mathrm{~nm}$ of argon- krypton laser. With the purpose to eliminate local overheating the samples, laser radiation power did not exceed $1 \mathrm{~mW} / \mathrm{cm}^{2}$. 
Table 1. Changes of tetragonal lattice parameters and the values of "guest" loading of $\mathrm{TiO}_{2}$ as a result of laser irradiation.

\begin{tabular}{|c|c|c|c|c|c|c|}
\hline \multirow{2}{*}{$\begin{array}{c}\text { № } \\
\text { samp } \\
\text { le }\end{array}$} & \multirow{2}{*}{$\begin{array}{l}\text { Energy in the } \\
\text { impulse E, } \\
\text { Joule }\end{array}$} & \multirow{2}{*}{$\begin{array}{l}\text { Irradiation } \\
\text { time, min. }\end{array}$} & \multicolumn{2}{|c|}{ Lattice parameters, E } & \multirow{2}{*}{$\begin{array}{l}\mathrm{Li}^{+} \text {"Guest” } \\
\text { intercalation } \\
\text { degree }\end{array}$} & \multirow{2}{*}{$\begin{array}{c}\text { Coherent- } \\
\text { scattering region, }\end{array}$} \\
\hline & & & $a$ & $c$ & & \\
\hline 1 & 0 & 0 & 3.7884 & 9.5086 & 1.87 & 95 \\
\hline 2 & 0.02 & 4.5 & 3.7874 & 9.5057 & 1.43 & 95 \\
\hline 3 & 0.02 & 5 & 3.7878 & 9.5039 & 2.65 & 93 \\
\hline 4 & 0.02 & 5.5 & 3.7866 & 9.5027 & 1.78 & 93 \\
\hline 5 & 0.03 & 4.5 & 3.7884 & 9.5034 & 2.07 & 95 \\
\hline 6 & 0.03 & 5 & 3.7872 & 9.5054 & 2.32 & 94 \\
\hline 7 & 0.03 & 5.5 & 3.7873 & 9.5050 & 2.12 & 95 \\
\hline 8 & 0.04 & 4,5 & 3.7874 & 9.5042 & 2.11 & 94 \\
\hline 9 & 0.04 & 5 & 3.7866 & 9.5016 & 1.47 & 94 \\
\hline 10 & 0.04 & 5.5 & 3.7877 & 9.5033 & 3.50 & 95 \\
\hline
\end{tabular}

\section{Results and discussion}

$\mathrm{TiO}_{2}$ with the anatase structure belongs to the spatial group of $D_{4 h}^{19}$ symmetry. In this structure, the titanium ions are surrounded by six ions of oxygen that are located in vertexes of the partly distorted octahedron, at the same time three ions of metal that co-ordinate each of anions lie in the vertexes of semi-perfect triangle. Accordingly to the theoretical group analysis for tetragonal anatase structure, optical phonon modes active in the process of Raman scattering for G-points of Brillouin center zone $(\vec{q}=0)$ can be presented by six nonreducible representations: $\mathrm{G}=3 E_{g}+2 B_{l g}+A_{l g}$. As a result, it is possible to observe in the experimental Raman spectrum $3 E_{g}$ nonpolar modes with frequency positions 143, 197 and $639 \mathrm{~cm}^{-1}$ [4] (see, Fig. 1 as $E_{g}(1)$, $E_{g}(2)$ and $E_{g}(3)$, accordingly), 2B $\mathrm{B}_{1 \mathrm{~g}}$ nonpolar modes at 399 and $\sim 519 \mathrm{~cm}^{-1}$ and $\mathrm{A}_{1 \mathrm{~g}}$ mode at $\sim 513 \mathrm{~cm}^{-1}$. Phonon $\mathrm{B}_{1 \mathrm{~g}}$ modes nearly $\sim 513$ and $\sim 519 \mathrm{~cm}^{-1}$ are well spectrally separated only at low temperatures [5].

The narrow and very intense phonon band at 143 $\mathrm{cm}^{-1} E_{g}(1)$ corresponds to oscillation of bridges between the octahedrons of $\mathrm{TiO}_{6}$. Oscillations at $143,197 \mathrm{~cm}^{-1}$ $\left(E_{g}(1), E_{g}(2)\right.$ modes) and $393 \mathrm{~cm}^{-1}\left(B_{l g}\right.$ mode) are mainly $\mathrm{O}-\mathrm{Ti}-\mathrm{O}$ bending. The high-frequency bands at $639 \mathrm{~cm}^{-1}$ $\left(E_{g}(3)\right.$ mode) and at $514 \mathrm{~cm}^{-1}\left(A_{l g}\right.$ mode $)$ are Ti-O strain oscillation (valency).

In our case for the unirradiated anatase, nc- $\mathrm{TiO}_{2}$ samples frequency position of $E_{g}(1)$ phonon band is 145 $\mathrm{cm}^{-1}$, which is higher as compared to the bulk $\mathrm{TiO}_{2}(143$ $\left.\mathrm{cm}^{-1}\right)$. This effect can be conditioned by decreasing of crystal size [6], increasing of superficial strains [7], nonstoichiometry of chemical composition and by surface oxidization of particles [8], change of the lattice parameter [9]. The size of $\mathrm{TiO}_{2}$ nanocrystals (found from the analysis of the low-frequency $E_{\mathrm{g}}(1)$ of phonon mode) is about $12 \mathrm{~nm}$ [6]. In addition, broadening and shifting frequency $\left(143 \mathrm{~cm}^{-1}\right)$ of $E_{\mathrm{g}}(1)$ mode in the paper [8] is connected to the «stoichiometry defects» in oxygen sublattice: at disturbance of the stoichiometry ratio $\mathrm{O} / \mathrm{Ti}$ from 2.0 down to 1.89 there were broadening and highfrequency shift of $E_{\mathrm{g}}(1)$ mode more than by $10 \mathrm{~cm}^{-1}$ [10].

The authors also studied the effect of laser irradiation with the energy influence in the $\mathrm{TiO}_{2}$ transparence area on its phonon spectra, which is not studied enough up tu date. From Fig. 1, we can see that with increasing the nanocrystalline (nc) $\mathrm{TiO}_{2}$ laser irradiation dose up to $0.04 \mathrm{~J}$, the growth of integral intensity takes place for all phonon bands. The band intensity of $E_{g}(1)$ mode increases almost 10-fold (Fig. 2) and $B_{1 g}$ and $E_{g}(2)$ mode - by $\sim 1.7$ times. This effect of dominant intensity increase for $E_{g}(1)$ mode can be conditioned by improvement of structural order in $\mathrm{TiO}_{2}$ inside the areas that connect $\mathrm{TiO}_{6}$ octahedrons. It should be mentioned that with increase of the irradiated dose the frequency of $E_{g}(1)$ of phonon mode decreases from $\sim 145.0$ down to $\sim 143 / 5 \mathrm{~cm}^{-1}$ with its practically stable halfwidth $\left(\Delta \approx 8.0 \ldots 8.2 \mathrm{~cm}^{-1}\right)$ (Fig. 3). This effect of changing parameters for other phonon bands of $n c-\mathrm{TiO}_{2}$ with the increase of irradiation dose is considerably lower. For example, for $B_{1 g}$ mode $\Delta \omega \approx 397.8-396.8 \mathrm{~cm}^{-1}$ and $\Delta \sim 21.0-21.6 \mathrm{~cm}^{-1}$, and for $E_{g}(3)$ mode $\Delta \omega \approx 640.5$ $-639.8 \mathrm{~cm}^{-1}, \Delta \sim 22,0-22,5 \mathrm{~cm}^{-1}$. One of the main reason of substantial broadening $B_{1 g}$ and $E_{g}(3)$ phonon modes in Raman spectra is the presence of defects in small crystallites [11], which shows their high sensitivity to the defects as compared to the intensity of $143 \mathrm{~cm}^{-1}$ $E_{g}(1)$ mode [12].

It should be noted that the small shift of frequency and change in the halfwidth of phonon lines $E_{g}$ and $B_{1 g}$ in Raman spectra are not necessary conditioned by the change of $\mathrm{TiO}_{2}$ nanoareas. In each case, the change of Raman phonon spectra can have its own peculiarities, which is determined by nonstoichiometry of elemental and phase composition as well as by dispersion of dimensions. Important factors that influence on the 
frequency position of phonon lines in $\mathrm{TiO}_{2}$ nanocrystals can be vacancies in the oxygen sublattice, internal microstrains, conditions at the particle surface, type and concentration of different active superficial centers, related to the adsorbed oxygen and hydroxyl molecular complexes, etc. For example, one of the reason of internal microstrain changes can be nc- $\mathrm{TiO}_{2}$ surface oxidation due to oxygen that appears when reducing the coordinate-unsaturated cations $\mathrm{Ti}^{4+}$ under irradiation by visible light with the wavelength 600 up to $800 \mathrm{~nm}$ [8].

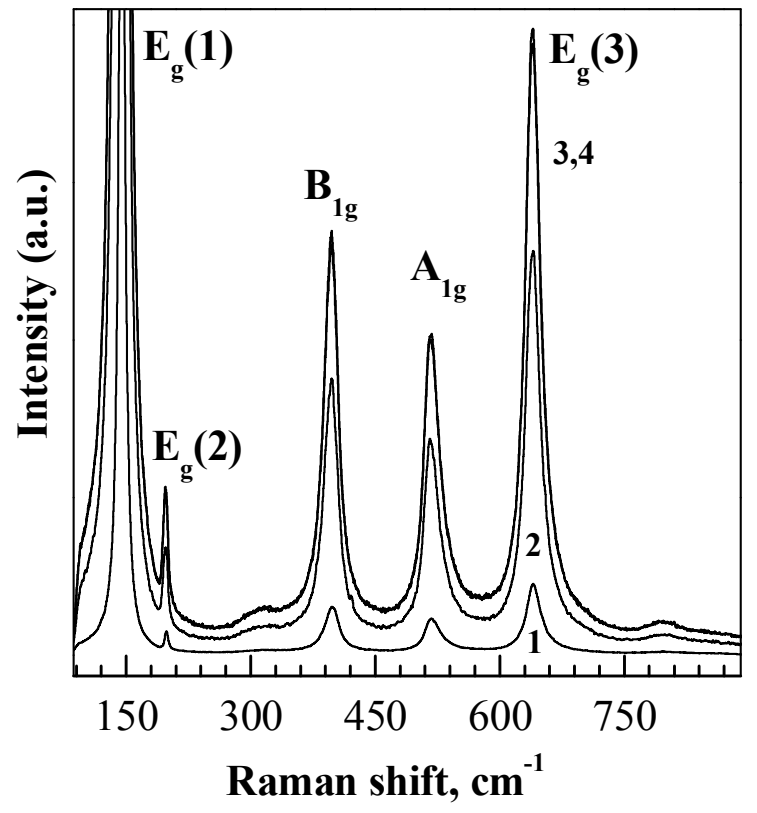

Fig. 1. Raman spectra of $n c-\mathrm{TiO}_{2}$ : initial (curve 1) and irradiated by laser irradiation with the dose of $0.02,0.03,004 \mathrm{~J}$ (curves 2, 3, 4, accordingly). $\mathrm{T}=300 \mathrm{~K} ; \lambda_{\mathrm{exc}}=488.0 \mathrm{~nm}$.

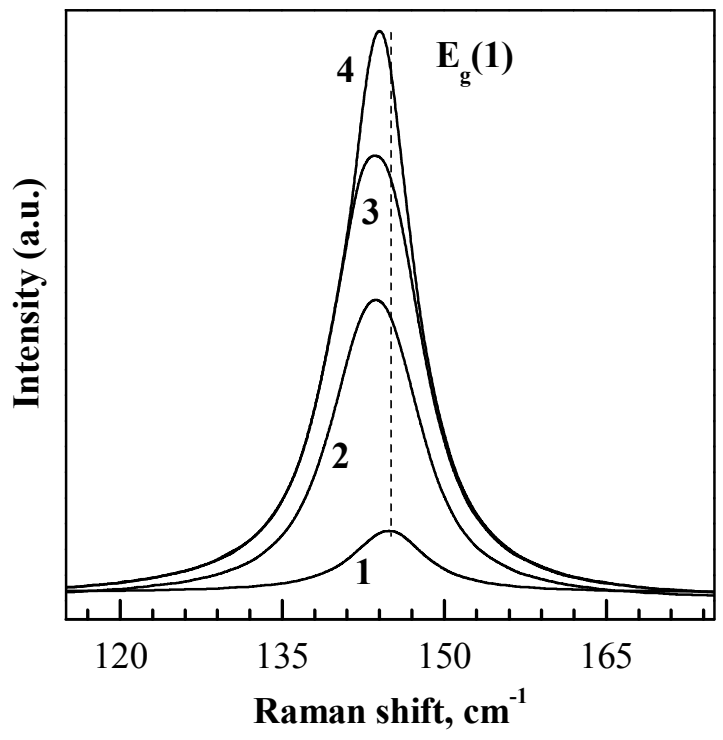

Fig. 2. $\mathrm{E}_{\mathrm{g}}(1)$ mode of $\mathrm{nc}-\mathrm{TiO}_{2}$ at $144 \mathrm{~cm}^{-1}$ : spectra of initial (curve 1) and irradiated by laser irradiation with the dose 0.02 , $0.03,0.04 \mathrm{~J}$ (curves 2, 3, 4, accordingly). $\mathrm{T}=300 \mathrm{~K}$. $\lambda_{\mathrm{exc}}=488.0 \mathrm{~nm}$.

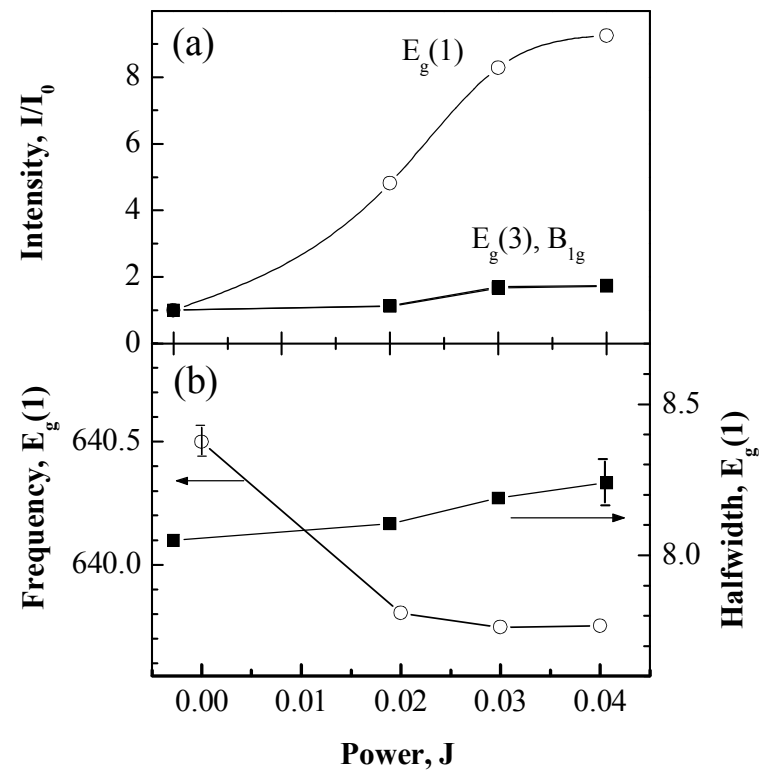

Fig. 3. Relative intensity change $E_{g}(1), E_{g}(3), B_{1 g}$ of phonon mode (a), frequency and halfwidth of $\mathrm{E}_{\mathrm{g}}(1)$ mode vs laser irradiation power (b). T $=300 \mathrm{~K} . \lambda_{\mathrm{exc}}=488.0 \mathrm{~nm}$.

Also, we researched the influence of the process of electrochemical intercalation in $\mathrm{TiO}_{2}$ on its phonon spectra at different stages of $x$ intercalation. The nonpolar mode with the frequency positions 144,168 and $774 \mathrm{~cm}^{-1}\left(E_{g}(1), E_{g}(2)\right.$ and $E_{g}(3)$, accordingly), $2 B_{1 g}$ nonpolar mode at $\sim 444 \mathrm{~cm}^{-1}$ and $A_{1 g}$ mode at $\sim 604$ $\mathrm{cm}^{-1}$ are observed in the experimental Raman spectrum (Fig. 4).

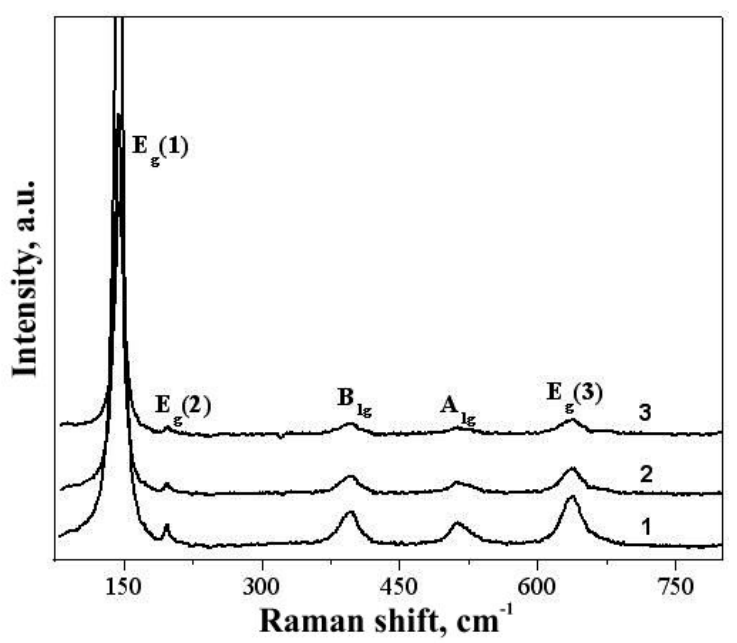

Fig. 4. Raman spectra of $\mathrm{nc}-\mathrm{TiO}_{2}$ intercalated by lithium at $x=$ 0.05 (curve 1), $x=0.10$ (curve 2) and $x=0.15$ (curve 3). $\mathrm{T}=300 \mathrm{~K}, \lambda=488.0 \mathrm{~nm}$.

Accordingly to Fig. 4, at the increase of intercalation degree $x$ for $\mathrm{nc}^{-\mathrm{TiO}_{2}}$ to up to 0.15 the decreasing of all phonon bands integral intensities takes 
place. The intensity of the band for $E_{\mathrm{g}}(1)$ mode decreases almost by 3.5 times (Fig. 5), and $B_{1 \mathrm{~g}}, E_{g}(2)$ modes by $\sim 2$ times. This effect of dominant decrease in the $E_{g}(1)$ mode intensity can be conditioned by $\mathrm{TiO}_{2}$ deformation in the $\mathrm{TiO}_{6}$ coordination octahedron bonding structure areas during lithium intercalation [13], the degree of which grows gradually. In our case (Fig. 5), for the intercalated samples of anatase nc- $\mathrm{TiO}_{2}$ with $x=0.15$ the frequency position of the phonon band $E_{g}(1)$ mode is $145 \mathrm{~cm}^{-1}$, which is some higher as compared to the samples intercalated to $x=0.05$ $\left(144 \mathrm{~cm}^{-1}\right)$. This effect can be conditioned by the lattice parameter changes as a result of lithium diffusion [14] and increase of superficial strains. It is important to note that the change of $E_{g}(1)$ phonon lines halfwidth in the Raman spectrum with the change of the intercalated lithium amount can be determined by the phase composition nonstoichiometry of intercalated titanium, which proves the uneven filling the vacant positions by lithium atoms in the bulk of anatase nanocrystal particles.

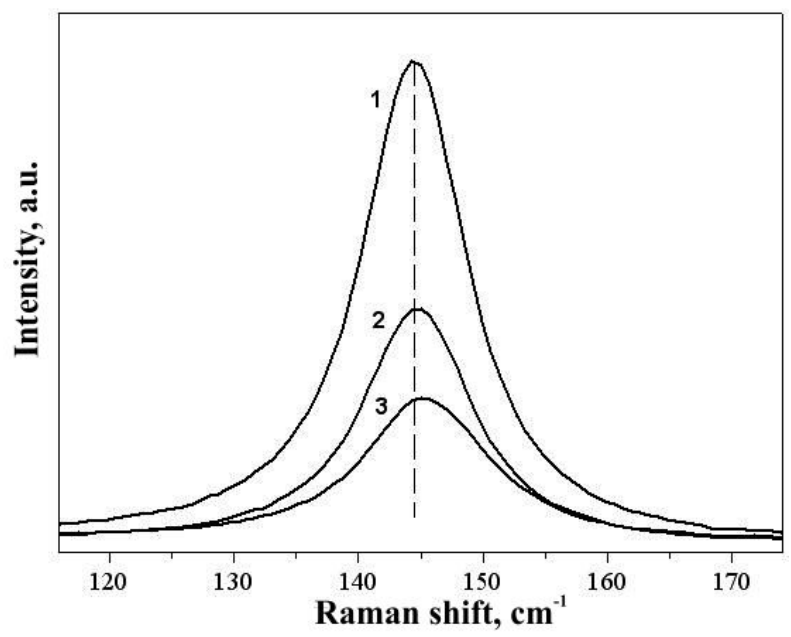

Fig. 5. $E_{g}(1)$ mode $144 \mathrm{~cm}^{-1}$ of nc- $\mathrm{TiO}_{2}$ intercalated by lithium at $x=0.05$ (curve 1), $x=0.10$ (curve 2) and $x=0.15$ (curve 3 ). $\mathrm{T}=300 \mathrm{~K} \cdot \lambda=488.0 \mathrm{~nm}$.

\section{Conclusions}

Considerable growth of the $E_{g}(1)$ mode intensity can be conditioned by the laser irradiated $\mathrm{TiO}_{2}$ structural arrangement improvement, and reason of considerable broadening of $B_{l g}$ and $E_{g}(3)$ phonon modes in the Raman spectrum is the small crystals defects. Decreasing the $E_{g}(1)$ mode intensity with increasing the lithium intercalation degree is conditioned by the intercalation caused structural deformation in $\mathrm{TiO}_{2}$ nanocrystals, which proves insertion of the lithium atoms and their diffusion in the host-material structure.

\section{References}

1. Ostafiychuk B.K. Structural changes of nanodispersed $\mathrm{TiO}_{2}$ as a result of laser irradiation / B.K. Ostafiychuk, M.Ya. Segin, I.I. Budzulyak etc. // Physics and chemistry of solid states. - 2009. V. 10, № 4. - P. 773 - 776.

2. Kosova N.V. High dispersed materials for lithium storage: mechanic-chemical approach / N.V. Kosova, Ye.T. Devyatkina, D.I.Osincev // Journal of structural chemistry. - 2004. - V. 45. - P. 144 148.

3. Myronyuk I.F. Lithium intercalation inTiO energy relief, influence on electronic structure and peculiarities of thermodynamic process / I.F. Myronyuk, V.V.Lobanov, B.K. Ostafiychuk, I.I.Grygorchak, R.V.Ilnytskyy, R.P. Lisovskyy // Bulletin of Precarpatian university. Mathematics. Physics, 2000. - \# 1. - P.148-159.

4. Swamy V. Finite-size and pressure effects on the Raman spectrum of nanocrystalline anatase $\mathrm{TiO}_{2} /$ V. Swamy, A. Kuznetsov, L. S. Dubrovinsky et al. // Phys. Rev. B. - 2005. - V.71. - P. 184302.

5. Mikami M. Lattice dynamics and dielectric properties of $\mathrm{TiO}_{2}$ anatase: A first-principles study / M. Mikami, S. Nakamura, O. Kitao, H. Arakawa // Phys. Rev. B. - 2002. - V. 66. - P. 155213.

6. Zhang W. F. Raman scattering study on anatase $\mathrm{TiO}_{2}$ nanocrystals / W. F. Zhang, Y. L. He, M. S. Zhang, Z. Yin and Q. Chen // J. Phys. D: Appl. Phys. - 2000. - V.33. - P. 912 - 916.

7. Lee S.W. Formation of anatase $\mathrm{TiO}_{2}$ nanoparticles on carbon nanotubes / S.W. Lee, W.M. Sigmund // Chemical Communications. - 2003. - V.6. - P. 780 -781 .

8. Li Bassi A. Raman spectroscopy characterization of titania nanoparticles produced by flame pyrolysis: The influence of size and stoichiometry / A. Li Bassi, D. Cattaneo, V. Russo, C.E. Bottani, E. Barborini, T. Mazza, P. Piseri, P. Milani, F.O. Ernst, K. Wegner, S.E. Pratsinis // J. Appl. Phys. 2005. - V.98. - P. 074305.

9. Spanier J.E. Size-dependent properties of $\mathrm{CeO}_{2-y}$ nanoparticles as studied by Raman scattering / J.E. Spanier, R.D. Robinson, F. Zhang, S.-W. Chan, and I.P. Herman // Phys. Rev. B. - 2001. - V.64, P. 245407.

10. Parker J.C. Calibration of the Raman spectrum to the oxygen stoichiometry of nanophase $\mathrm{TiO}_{2} /$ J.C. Parker, R.W. Siegel //Appl. Phys. Lett. -1990. V.57, № 9. - P. 943 - 945.

11. Sahoo S. Phonon confinement and substitutional disorder in $\mathrm{Cd}_{1-x} \mathrm{Zn}_{x} \mathrm{~S}$ nanocrystals / S. Sahoo, S. Dhara, V. Sivasubramanian, S. Kalavathi, A.K. Arora // J. Raman Spectrosc. - 2009. - V.40. - P. 1050 - 1054.

12. Balaji S. Phonon confinement studies in nanocrystalline anatase- $\mathrm{TiO}_{2}$ thin films by micro Raman spectroscopy / S. Balaji, Y. Djaoued, J. 
Robichaud // J. Raman Spectrosc. -2006. - V.37. P. $1416-1422$.

13. Siegel R.W. Characterization of nanoparticles and nanophase materials // Aerosol methods and advanced techniques for nanoparticle science and nanopowder technology. Proceedings European science foundation explorative workshop. Duisburg.- 1993. - P. 15.

14. Velychko O.V. Phase separation in lithium intercalated anatase: A theory / O.V. Velychko, I.V. Stasyuk // Condensed Matter Physics. - 2009. - V.12, № 2. - P. $249-266$. 